\title{
El lenguaje de la ciudad postpostmoderna: la Nueva Nueva York de Futurama
}

\author{
Fernando Ángel MoReno e Ivana PALIBRK \\ Departamento de Lengua Española, Teoría de la Literatura y \\ Literatura Comparada \\ Universidad Complutense de Madrid \\ famoreno@filol.ucm.es
}

\begin{abstract}
Resumen
Para ejemplificar el funcionamiento literario de toda ficción prospectiva, se ha escogido la teleserie Futurama y, en concreto, su ciudad de Nueva Nueva York, que parodia la ciudad real de Nueva York y, por extensión, toda gran ciudad occidental. El funcionamiento de la ciudad prospectiva parodiada es analizado desde las teorías de Viktor Sklovski, Walter Mignolo y Paul Ricoeur, en cuanto a la metaforización desde procesos de desfamiliarización y semantización. A partir de estos principios teóricos, se ha analizado esta ciudad en general y sus elementos urbanos en particular. Para estos elementos se ha empleado la representatividad de cada uno de los personajes principales en cuanto a su relación con la propia ciudad.
\end{abstract}

Palabras clave: ciudad, prospectiva, ciencia ficción, Futurama, teleserie, parodia.

Title: The Language of the Postpostmodernist City: Futurama's New New York City

\section{Abstract}

In order to exemplify the literary functioning of the prospective fiction, television series Futurama is chosen, and more precisely the city of New New York, which represents the parody of the real New York and therefore the parody of every big occidental city. The functioning of the parody of the prospective city is being analyzed starting from the theories of Viktor Shklovsky, Walter Mignolo and Paul Ricoeur, which are related to the metaphorization and the processes of defamiliarization and semantization. Starting from these theoretic principles the city in general and especially its urban elements are analyzed. Each of the main characters is used as a representative of these elements based on its relations to the city itself.

Keywords: city, prospective, science fiction, Futurama, television series, parody.

\section{Índice}

1. Introducción

1.1. Desfamiliarizándonos...

1.2. Semantizándonos...

1.3. Metaforizándonos...

2. El tono tierno y cínico

3. Nueva Nueva York: Ios ciudadanos en la ciudad

3.1. Leela 
3.2. Fry y el profesor Farnsworth

3.3. Bender

3.4. Amy y Zoidberg: la adaptada y el inadaptado

3.5. Hermes

6. Conclusiones

En el amplio panorama, la ciudad parece un gigantesco ser vivo. O el conjunto de una multitud de corpúsculos entrelazados. Innumerables vasos sanguíneos se extienden hasta el último rincón de ese cuerpo imposible de definir, transportan la sangre, renuevan sin descanso las células. Envían información nueva y retiran información vieja. Envían consumo nuevo y retiran consumo viejo. Envían contradicciones nuevas y retiran contradicciones viejas. Al ritmo de las pulsaciones del corazón, parpadea todo el cuerpo, se inflama de fiebre, bulle. La medianoche se acerca $y$, una vez superado el momento de máxima actividad, el metabolismo basal sigue, sin flaquear, a fin de mantener el cuerpo con vida. Suyo es el zumbido que emite la ciudad en un bajo sostenido. Un zumbido sin vicisitudes, monótono, aunque lleno de presentimientos.

(Haruki Murakami, After Dark)

\section{Introducción}

¿Por qué es divertido ver Futurama?

Bueno, ahí están Bender; el loco del profesor Farnsworth; Leela tampoco falla, capítulo tras capítulo; los chistes son muy ocurrentes; las cabezas de los famosos suelen ser ingeniosas y sorprendentes. $Y$, ah, sí, porque hay cabinas de suicidios en las que por un cuarto de dólar eliges tu propia muerte. Todo es muy familiar, pero no debería serlo. ¿O sí?

Quizás la pregunta debería ser: ¿por qué consideramos Futurama un producto de calidad? ¿Por qué lo consideramos digno de estudio? Porque nos presenta la suma de una ciudad. Es cierto. $O$, al menos, nos muestra una ciudad perspectivamente unidireccionada, a lo occidental. Pero al fin y al cabo esa ciudad es Nueva Nueva York, el centro del universo, justificación para innumerables exageraciones.

Como toda ciudad. ¿O no insiste cada persona ajena a la ciudad, cuando la invade en nuestra vida cotidiana y real, en que todo en dicha ciudad le resulta exagerado?

Sigue siendo familiar, ¿no? Parece que lo familiar es muy importante para que Futurama nos resulte divertido $y$, al mismo tiempo, digno de estudio. 
iPero hay cabinas de suicidios, extraterrestres, furcias-robot, tubos transportadores...! ¿Cómo es que nos resulta familiar?

De acuerdo, lo aceptamos: todo eso no resulta familiar.

Pero el suicidio nos resulta familiar. La afición de esos extraterrestres por las teleseries nos resulta familiar. La existencia de prostitutas nos resulta familiar. Los tubos transportadores... No, eso no.

Resulta evidente que en la Nueva Nueva York de Futurama lo familiar y lo desfamiliarizado a menudo se funden en un mismo elemento narrativo. ¿Qué mejor ejemplo para ilustrar con un ejemplo suficientemente variado y rico el concepto de "ciudad prospectiva" que se ha trabajado en este dossier y en el del anterior número de esta misma revista?

Podríamos citar en este momento al menos tres teorías que tratan esta peculiaridad, entre muchas otras: la de la semantización, de Walter Mignolo (1981); la de la desfamiliarización, de Víktor Sklovski (1917), y la desarrollada por Paul Ricoeur sobre la metáfora (1975). Las tres nos sirven para iluminar esta curiosa paradoja futuramística.

\subsection{Desfamiliarizándonos...}

La del formalista ruso es sobradamente conocida. Ya en los primeros textos de Sklovski (1917), se incide en que solo contra el fondo de lo familiar nos llega y nos impresiona lo no familiar, idea recogida por Jakobson y otros teóricos posteriores. Si consideramos -con aquellos primeros teóricos de la teoría de la literatura- que el efecto de extrañamiento producido por la desfamiliarización es lo que nos permite percibir el mundo como si lo viéramos por primera vez, comenzaremos a entender que el juego de la Nueva Nueva York en Futurama consiste en volver a contemplar nuestras ciudades desde fuera. Como si las viéramos por primera vez.

Y por eso es divertida, porque este proceso se basa en la parodia. No obstante, no se trata de una única parodia, sino de un juego de parodias entre las cuales las más importantes son la de la ciudad y la del propio género de la ciencia ficción. También un formalista ruso, Tiniánov, explicaba que una obra del pasado jamás imita una obra del presente, sino que la recrea, la transforma. Sin embargo, esta recreación puede ser positiva (en cuyo caso nos encontraríamos ante una "estilización") o cómica: la parodia (Sanmartín 2008: 215). Es decir, en Futurama se recrean paródicamente conceptos reales y ficcionales de ciudades mediante la recreación paródica del género de la ciencia ficción, pero con evidentes homenajes a ambas instituciones. 


\subsection{Semantizándonos...}

Walter Mignolo (1981) defiende que en la mayor parte de las obras ficcionales se produce un fenómeno de semantización. Esta "semantización" es el proceso por el cual la fuerza del pacto de ficción se va apoyando en determinados elementos lingüísticos, palabras, oraciones... que nos van "convenciendo" de que lo narrado es "real", aunque ciertos elementos parecieran indicarnos lo contrario. Las referencias a nuestro propio mundo dentro de una novela prospectiva funcionan, como es obvio, a partir de elementos semantizadores que nos permiten acomodarnos a las exageraciones sin que nos resulten absolutamente ajenas.

Por consiguiente, si bien dicho proceso se desarrolla en textos ficcionales realistas, su importancia es mucho mayor en géneros proyectivos como la literatura fantástica o la prospectiva.

Por ejemplo, el propio personaje de Fry representa en sí mismo un elemento semantizador, que nos permite acceder al año 3000 de Nueva Nueva York desde un ancla familiar ${ }^{1}$. Que le sorprenda una mujer con un solo ojo o el departir tranquilamente con un robot permite que nos encontremos menos incómodos durante nuestros paseos por esta ciudad del futuro.

No obstante, en Futurama existe un doble juego paródico de semantización que permite crear juegos de familiarización y desfamiliarización con consecuencias críticas, estéticas y humorísticas relevantes. El juego consiste en que a menudo lo extraño, lo no familiar, se encuentra en un elemento de ciencia ficción. Por ejemplo, el hecho de que un tipo venda órganos humanos en medio de la calle. No obstante, la actitud de los personajes, completamente habituados a la mercadería fraudulenta nos resulta familiar, pues la mayor parte de los espectadores de la serie han vivido una experiencia similar en una ciudad. Es decir, la reacción urbana prototípica funciona como elemento semantizador para lo extraño de la venta. Sin embargo, al mismo tiempo, esa misma familiaridad implica una calma que no sería lógica en nuestro mundo real. Por consiguiente, la reacción calmada de los personajes representa al mismo tiempo familiarización y desfamiliarización. Este efecto paradójico es característico del funcionamiento de las metáforas.

\subsection{Metaforizándonos...}

Defiende Paul Ricoeur que "una metáfora es una creación instantánea, una innovación semántica que no tiene reconocimiento en el lenguaje ya establecido, y que solo existe debido a la atribución de un predicado inusual e inesperado. La metáfora, por tanto, es más

1 ¿Dijimos que Futurama se desarrolla en el año 3000? ¿No? Futurama se desarrolla en el año 3000. 
la resolución de un enigma que una simple asociación basada en la semejanza; está constituida por la resolución de una disonancia semántica" (1975: 65).

En la parodia prospectiva, esta disonancia semántica salta a la vista: un tipo vende órganos humanos en plena calle, pero los ciudadanos lo toman como algo cotidiano. Aunque Ricoeur se refiere, evidentemente, a imágenes mucho más concretas y a combinaciones de términos, en realidad se trata de una simbiosis entre diferentes conjuntos semánticos. Por ejemplo, cuando Bécquer afirma que "cuando me lo contaron sentí el frío de una hoja de acero en las entrañas", ese frío de una hoja de acero nos crea una desfamiliarización: "iHey! Este tío dice que siente una hoja de acero en las entrañas...". Pero nuestra razón nos dice que eso no es posible; es decir, se produce en nuestra mente una disonancia cognitiva. Pero esa misma razón acude en nuestro auxilio y nos informa de que seguramente el poeta pretende equiparar ciertos semas contenidos en la idea de que nuestras entrañas sean atravesadas por una hoja de acero ("dureza", "invasión", "duelo", "combate con espadas", "dolor", "novela de espada y brujería", "arma", "muerte"...). Para resolver esta disonancia, asumimos que algunos de esos semas ("dureza", "invasión", "dolor") pretenden equipararse con una sensación producida por una noticia verbal.

Del mismo modo, nuestra razón supera la disonancia cognitiva producida por el hecho de que ciertos ciudadanos del futuro no se sorprendan por el hecho de que alguien les haga una oferta callejera de órganos humanos.

La resolución de esta disonancia es bien sencilla: tampoco en las grandes ciudades nos sorprenden traumáticos hechos que deberían sorprendernos. Por tanto, las grandes ciudades resultan, de algún modo, tan salvajes y horribles como Nueva Nueva York, pero necesitamos de la resolución de una disonancia cognitiva para contemplarlas como si las contempláramos por primera vez. Todo ello es posible gracias a un proceso previo de semantización (Moreno 2010: 181-183).

La Nueva Nueva York de Futurama es, evidentemente, una recreación de nuestras propias ciudades, para actualizar nuestra percepción de las mismas y de nuestra actitud ante ellas.

Para entrar en el análisis de todas las ciudades prospectivas contenidas en Nueva Nueva York, se precisa presentar la serie.

\section{El tono tierno y cínico}

Futurama es una teleserie prospectiva de animación creada por Matt Groening, conocido también por haber creado la teleserie The Simpsons. Esta serie de ciencia ficción se transmitió primero durante cuatro temporadas (1999-2003), hasta que fue cancelada. A continuación se filmaron cuatro largometrajes, conocidos 
familiarmente como "La quinta temporada", y se reanudó como teleserie en 2010. Cada capítulo de la serie dura en torno a veinte minutos. Los largometrajes se acercan a los noventa minutos de duración.

La serie narra las aventuras de un grupo heterogéneo de individuos de una empresa de transporte espacial. Dicha empresa es propiedad del profesor Farnsworth, un científico loco y extravagante. El piloto de la nave es la cíclope Leela, una mujer aguerrida de fuerte carácter $y$, al mismo tiempo, de extrema sensibilidad. La acompañan Fry, un chico del siglo XX que ha despertado en esta época; Bender, un robot que representa la mayor parte de las bajezas humanas a pesar de su amistad por Fry y Leela; Amy, una frívola chica oriental, hija de millonarios; el doctor Zoidberg, médico alienígena absolutamente inadaptado a las costumbres humanas, y Hermes, un contable jamaicano, casado y con hijos, alegre y familiar.

Todos ellos viven en Nueva Nueva York, una ciudad levantada sobre la Nueva York del siglo XX. Muchos de los episodios transcurren en esta ciudad, aunque por la propia situación de partida muchos otros tienen lugar en lejanos planetas que, contrastivamente, representan lo opuesto a la gran ciudad, salvo en contadas excepciones de visitas a otras ciudades. Es decir, el ámbito rural en Futurama no queda representado por la sierra de Madrid, ni por los pueblitos de los Estados Unidos profundos, ni por las granjas sencillas de las gentes humildes de la pampa argentina. No. El ámbito rural en Futurama es el cosmos, con sus asteroides, cometas, agujeros negros, razas alienígenas y la inmensidad oscura del espacio profundo.

Ya encontramos de este modo un profundo juego paródico de familiarización y desfamiliarización entre el espacio familiar de las calles y los parques urbanos, por un lado, y la hiperbolizada extrañeza de lo alienígena, por el otro (Moreno 2011a). Todo ello se presenta en todo momento bajo el cinismo que hemos descrito, con píldoras frecuentes que no encajan mal con los términos de la catarsis aristotélica.

La serie sigue la tradición del cartoon absurdo tradicional, especialmente conocido por los personajes de la Warner, y las series de animación centradas en una corrosiva crítica social, como la propia The Simpsons o Family Guy. En este sentido, la serie abunda en referencias a nuestro tiempo, tanto directas como indirectas, desde casi cualquier punto de vista social planteable: feminismo, colonialismo, relaciones sentimentales, capitalismo, influencia de los medios de comunicación de masas, religión, gobierno estatal, ejército o movimientos pacifistas, entre muchos otros.

No obstante, el juego semantizador y desfamiliarizador que ya hemos presentado se realiza siempre desde un punto de vista 
descriptivo, sin mensajes moralistas evidentes $\mathrm{y}$, a menudo, con cierta humanización y ternura hacia el elemento social criticado.

De este modo, cualquier forma de inteligencia, especialmente la humana, se muestra como una acumulación de defectos y bajezas, pero -desde el punto de vista perlocutivo- hacia una catarsis provocada por el temor y la compasión hacia los seres criticados. No es raro, en este sentido, encontrar al más feroz alienígena, destructor de mundos, devorador de humanos, en su llanto desvalido, necesitado de un tierno abrazo. En este juego de semantización de los sentimientos de los personajes, el efecto de familiarización tiende por tanto a una especie de comprensión psicológica. Sin embargo, tampoco es raro el momento de vuelta a la destrucción y a la muerte que puede suceder al momento de ternura, por lo que ese sentimiento catártico queda siempre difuminado bajo un indiferente cinismo. Podría decirse, incluso, que es el cinismo con que se contempla la falta de sentido y salvación del ser humano lo que permite aceptar con ternura todas estas bajezas. Sencillamente, si somos todos horribles... ¿por qué agobiarse buscándole un sentido o quejándonos?

Por consiguiente, no se puede tildar la serie de pesimista ni de amarga en un sentido profundo. Por este mismo motivo, la ciudad presentada no encaja completamente en ninguna de las dos divisiones sociales más frecuentes de la literatura prospectiva: la utopía y la distopía.

Los rasgos distópicos parecerían evidentes, en un principio. Nos encontramos, al fin y al cabo, con una ciudad cuyas costumbres -a menudo crueles e insensibles- son frecuentes e incluso aceptadas por la población. Sin embargo, el juego de familiarización y desfamiliarización que hemos descrito, junto al tierno cinismo con que se presenta, tamiza los defectos de esta sociedad al igualarlos con la nuestra. Una primera conclusión obvia sería que la serie nos presenta nuestra propia sociedad como una distopía; no obstante, el hecho de que la felicidad de los personajes dependa más de sí mismos que de las características de la ciudad descrita o de las sociedades en que viven, se contradice con la tradición de los relatos distópicos.

Nueva Nueva York, por consiguiente, representa más un telón de fondo para las realidades culturales contemporáneas -con gran frecuencia, simbólico- que una proyección agresiva de un estado totalitario. Si bien es cierto que esta sociedad está gobernada dictatorialmente por la cabeza de Richard Nixon desde la Casa Blanca, no parece encontrarse entre sus objetivos un férreo y deshumanizador control de las vidas de sus ciudadanos, como sí ocurre en distopías clásicas como Nosotros, de Evgueni Zamiatin; Un mundo feliz, de Aldous Huxley; 1984, de George Orwell; Farenheit 451, de Ray Bradbury, o Neuromante, de William Gibson. En todas 
estas obras, la ciudad prospectiva simboliza de un modo u otro la opresión del Estado; por ejemplo, a través de sus cámaras de vídeo, como en el caso de la novela de Orwell, o de sus edificios transparentes, como en la obra de Zamiatin. Por el contrario, Nueva Nueva York ha crecido como tantas ciudades reales: según las propias necesidades de habitabilidad, comercio y administración burocrática. En este sentido, representa tantas relaciones analógicas con las ciudades que habitamos en Occidente que se puede decir absolutamente que se trata simplemente de un trasunto paródico de ellas.

Los propios personajes de la serie, en diversas ocasiones, son incluso capaces de ver lo peor de la ciudad como concepto, pero al mismo tiempo, de apropiarse de ello sin un rechazo explícito, evidente. Parecen defender que, en la ciudad, el horror de lo conceptual se encuentra separado de la práctica de la cotidianeidad y que, por consiguiente, un personaje puede horrorizarse ante lo deshumanizado de un elemento sin, por ello, renunciar a usarlo. Lo apreciamos, por ejemplo, en el uso de las cabinas de suicidio, la venta de órganos por la calle y los dispensadores automáticos de crack, con el yonqui desolado porque la máquina se le ha tragado la moneda. De nuevo, el cinismo y la ternura marcan el tono urbano.

\section{Nueva Nueva York: los ciudadanos en la ciudad}

Como vamos viendo, no nos encontramos ante una analogía completa entre la propuesta de Futurama y cualquier ciudad del planeta. Nueva Nueva York continúa cierta línea egocéntrica occidental al tomar como punto de partida la ciudad que más se emplea para representar Occidente. No se trata tan solo de que los autores escriban sobre lo conocido, costumbre estética de evidente eficacia, sino que, entre todas las ciudades cercanas a ellos que pudieran haber escogido, han tomado la más representada por el cine hollywoodiense $y$, por consiguiente, la más emblemática de Occidente. No obstante, dicha relación simbólica entre la ciudad real de Nueva York y el resto de las ciudades occidentales no es gratuita. En ella podemos encontrar casi todos los elementos urbanos que caracterizan a las ciudades occidentales, así como conceptos, tipos de vivencias, de habitabilidad, de cotidianeidad característicos de nuestra sociedad.

Por otra parte, casi todas las grandes ciudades actuales comparten numerosos rasgos con Nueva York: Shanghái, Berlín, Tokio, Roma, El Cairo... encuentran mucho de su estilo propio en esta ciudad estadounidense, mientras que puede resultar más difícil encontrarlo en cualquier otra. Al fin y al cabo, cualquiera que haya pasado un tiempo en ella sabe de la convivencia de diferentes etnias, religiones, ideologías, modos de vida y clases sociales que fluyen por sus calles en comunión. 
Es como si Nueva York contuviera un poquito del alma de todas las grandes ciudades en alguno de sus rincones.

Es cierto que no sería la mejor elección para representar una ciudad africana o una ciudad andina. No podemos afirmar que ninguna de sus zonas comerciales pueda representar ni siquiera mínimamente las medinas de muchas ciudades musulmanas, como la de la ciudad de Fez.

Pero también es verdad que no existe ninguna otra ciudad que en sí misma recoja tantos elementos comunes al resto y, al mismo tiempo, resulte tan paradigmática en el inconsciente colectivo.

En definitiva, ¿podemos plantear que Nueva Nueva York permite o alguna otra ciudad, al menos en potencia, mostrar el espíritu de todas las culturas urbanas del mundo?

No. Para eso tenemos los planetas del espacio exterior. Invitamos a los lectores y compañeros investigadores a visitarlos en busca de aquellos detalles que echen en falta entre las calles de Nueva Nueva York.

De todos modos, si juntamos la ciudad con lo rural (es decir, el espacio exterior, el cosmos, el universo...), obtendremos una crítica que abarca numerosos estereotipos y prejuicios de todo el planeta. Siempre desde la parodia.

Por todo ello, Nueva Nueva York lleva mucho más allá todos los planteamientos de posmodernidad contenidos en el imaginario atribuido a Nueva York: globalización, fragmentación, sospecha, capitalismo, alienación, supresión del yo, anarquía... Es decir, si Nueva York es la postmodernidad, haciendo un chiste fácil, Nueva Nueva York sería la postpostmodernidad ${ }^{2}$.

$Y$, como hemos anunciado en la introducción, el concepto de ciudad lo crean sus ciudadanos. Por consiguiente, veamos cómo los personajes de Futurama configuran Nueva Nueva York.

\subsection{Leela}

Toda ciudad se construye destruyendo.

En el episodio piloto presenciamos cómo evoluciona Nueva Nueva York desde la Vieja Nueva York y de dónde salen su nombre y, por ende, su identidad. La destrucción, como ya sabemos, no conduce a la nada y el vacío, sino que genera, arraiga, como tras un incendio los árboles carbonizados sirven de sustrato al nuevo bosque. Resulta fundamental para entender el concepto de ciudad prospectiva ser conscientes de este proceso de creación/destrucción, exactamente del mismo modo en que funciona la desfamiliarización de la parodia.

2 Y así adelantamos a todos los que se preguntan qué viene después de la postmodernidad... pues... más postmodernidad. 
Una parodia crece a partir de la destrucción organizada y creativa del objeto parodiado. Del choque de ambos, parodiado y parodia, surge el sentido.

No obstante, los restos -como un recordatorio siniestro de lo que en un tiempo representaba la esencia de la ciudad- permanecen en el subsuelo y forman parte de la ciudad actual.

A través de esta línea, la serie es muy reiterativa en dos ideas fundamentales:

1) La sensación de eternidad indestructible de la gran metrópolis.

2) La destrucción de lo indestructible.

Para marcar el paso del tiempo, ya en el episodio piloto se nos muestran a través de una ventana algunas de las sucesivas destrucciones de la urbe.

La serie insiste mucho en el sentimiento de desestabilización de toda ciudad ${ }^{3}$. Lo que una vez parecía la ciudad indestructible -la Nueva York de más de ocho millones de habitantes, centro del universo occidental- se nos muestra una y otra vez como las cloacas subterráneas de una nueva ciudad que, por otra parte, una y otra vez se encuentra amenazada por diferentes posibilidades de destrucción (venganzas extraterrestres, monstruos enloquecidos, enorme cubo de basura, Santa Claus...).

Especialmente sintomático es el hecho de que la Nueva York que tanto nos impresiona y protagoniza noticias de periódicos y películas hollywoodienses es, en Futurama, el suburbio de los homeless ${ }^{4}$.

De estos suburbios surge Leela, la mutante. Recordemos un poco su historia.

Leela fue abandonada por sus padres en un orfanato, puesto que su apariencia no demasiado desagradable, deformada, podría favorecerle una vida cotidiana. Es decir, es falso que la gran ciudad cosmopolita acepte a todos por igual: el mutante, el desclasado, el individuo sin empleo oficial no tiene sitio entre individuos tan cotidianos y normales como los humanos, los robots y los extraterrestres. Siempre entre lo raro hay algo más raro para poder marginarlo.

Los guetos urbanos son muy frecuentes en la ficción prospectiva, como podemos ver en Minority Report, Hijo de los hombres, Blade Runner y tantas otras películas. Siempre nos aparece

3 Baudrillard y Morin (2003) han insistido en este principio de deseo de la destrucción cosmopolita. ¿Acaso se equivocan y todo proceso de destrucción no es un deseo morboso, sino un deseo de renovación?

${ }^{4}$ El término anglosajón no comparte su existencia con una palabra tan expresiva en castellano. 
en estos guetos algo mucho más extraño que lo extraño, con una lección evidente respecto al acostumbrado hábito de la marginación.

El gueto urbano se organiza según sus propias reglas o leyes, a partir de la Vieja Nueva York, de sus edificios emblemáticos, ahora semidestruidos. Aquí los edificios emblemáticos son símbolos del tempus fugit. Los mutantes de estos guetos urbanos viven de lo que los ciudadanos de los estratos superiores desechan. La culminación de la marginalidad se nos presenta cuando Bender debe deshacerse de unos residuos tóxicos tras muchas preocupaciones acerca de su reciclaje (4.1.) ${ }^{5}$. Evidentemente, los arroja a los guetos de la vieja ciudad a través de las alcantarillas, precisamente el único punto de luz, la única salida, la única conexión entre los estratos superiores y los inferiores.

Las deformaciones de los habitantes de este submundo respecto a la perfección de los humanos pudientes funciona como una perfecta analogía con la relación entre los edificios y la podredumbre de la vieja ciudad -en un tiempo gloriosa- y la futurista Nueva Nueva York.

El personaje de Leela marca un hecho trágico: la vieja Nueva York no es en todo caso un resto, una sombra, un recuerdo amargo, sino un barrio más de Nueva Nueva York. Un barrio que, ya sabemos por nuestras propias ciudades, conviene ignorar, tal y como Leela la ignora. Ella ni siquiera conoce su origen, como los habitantes de toda ciudad, en su mayor parte, ignoran el origen de sus grandezas y sus miserias urbanas. Sin embargo, una vez conectadas ambas, Leela se convierte en un verdadero representante de la simbiosis simbólica entre la ciudad subterránea y la ciudad del aire, en la que los ciudadanos se mueven en tubos aéreos transparentes y en brillantes naves luminosas cerca del cielo. Es decir, Leela se encuentra suficientemente deformada como para representar al gueto, pero aceptablemente integrada en cuanto a apariencia -muy atractiva apariencia en una ciudad muy estética- y costumbres. Así, el símbolo ofrece muchas facilidades para fácilmente percibido por el espectador.

\subsection{Fry y el profesor Farnsworth}

Si Leela es la conexión entre lo viejo destruido y lo nuevo reconstruido, Fry representa la conexión entre lo viejo cuando era nuevo y la realidad actual. Como ya hemos comentado, Fry es el principal vehículo de familiarización/desfamiliarización de Futurama, puesto que dirige con su mirada la mayor parte del proceso de semantización de la serie.

${ }^{5}$ Las referencias a capítulos indican en primer lugar el número de temporada y, a continuación, el del episodio dentro de dicha temporada. 
La mejor muestra de este proceso de contraste entre elementos divergentes, como deducíamos de las teorías de Ricoeur, es la aparente paradoja entre Fry y su descendiente (tatatatatata...ranieto), el profesor Farnsworth.

Fry, un chico joven, ingenuo y cotidianamente normal, es el pasado del anciano científico: amargado, cínico y adorablemente cruel. Si a este hecho unimos las constantes sorpresas de Fry ante el futuro de la ciudad, que siempre conllevan un ataque de sus amigos por su "primitivismo", la diferencia de psicologías con el anciano se vuelve aún más contradictoria.

Por otra parte, en Fry se manifiesta la ruptura con el pasado y las nuevas posibilidades ofrecidas por la nueva ciudad. Por ejemplo, en el capítulo piloto, al considerar un trabajo idéntico al que tenía en la vieja Nueva York, rompe en un gesto simbólico su brazalete identificador y se convierte en repartidor entre las estrellas. Si bien es de nuevo un repartidor, ahora la elección parte de él mismo y abre sus horizontes. En realidad es la nueva ciudad la que le ofrece todo el cosmos $^{6}$.

A nadie sorprende ni este giro en su vida, ni cuestiona la inmoralidad de su descendiente. La nueva ciudad se rige por normas distintas y el nuevo ciudadano debe adaptarse o abandonarla.

Fry, como todos los personajes, surge de una paradoja, de un error, de un "defecto" contradictorio. La parodia es fuerte porque enfrenta opuestos extremos.

En ningún personaje se aprecia con tanta intensidad este hecho como en el representante tradicional de la perfección en la literatura prospectiva: el robot, tal y como hace confesar a uno de ellos el gran ficcionador sobre el tema.

-Mírense ustedes mismos - dijo finalmente-. No lo digo con ánimo de desprecio, ipero mírense! El material del que están hechos es blando y fofo, sin la menor fuerza ni resistencia, y sometido a la energía obtenida de la ineficiente oxidación de materiales orgánicos... como eso. -Señaló con un dedo desaprobador a lo que quedaba del bocadillo de Donovan-. Periódicamente entran en coma, y la menor variación de temperatura, presión del aire, humedad o intensidad de la radiación afecta su eficiencia. Son ustedes temporales. Yo, por mi parte, soy un producto terminado. Absorbo directamente la energía eléctrica y la utilizo con una eficiencia de casi un cien por ciento. Estoy compuesto de fuerte metal, soy consciente todo el tiempo y puedo soportar fácilmente los cambios más extremos de mi entorno. Estos son hechos que, junto con la proposición evidente en sí misma de que ningún ser puede crear a otro ser superior a sí mismo, aplasta sus absurdas teorías reduciéndolas a la nada. (Asimov 1941: 220)

${ }^{6}$ Aunque, debemos aceptarlo, siga siendo repartidor: todo cambia para que todo siga igual. 


\subsection{Bender}

Bender representa la perfección imperfecta. Bender representa lo más ruin del ser humano. Bender representa a todos los robots de Nueva Nueva York. Los robots representan lo más ruin de la ciudad: lo más humano.

La infinidad de referencias, usos, símbolos, relaciones que aprovechan los creadores de Futurama de su concepción de "robot" comienza en su propio hábitat dentro de la ciudad. En su espacio personal, su vivienda, se nos muestra la eficiencia de la economía lógica y calculadora: para vivir no es preciso más que el espacio que ocupamos. El robot medio de Futurama habita un cubículo diminuto que contrasta de manera sorprendente $y$, de nuevo, paradójica con los inmensos espacios de la ciudad del futuro. De nuevo, dos términos opuestos -amplitud y estrechez-, ahora relacionados con perfección física y relaciones urbanas, provocan interpretaciones de analogía con nuestra vida cotidiana. La progresiva disminución del espacio vital en las ciudades modernas llega aquí a su máxima ridiculización ${ }^{7}$.

Sin embargo, es preciso destacar lo alienante de este elemento de la vida urbana. Por consiguiente, Fry - un humano- sirve aquí de contraste semantizador a través del cual evidenciar aún más la denuncia. Si no se tiene cuidado, la ciudad oprimirá al individuo, no solo simbólicamente, sino espacial, literalmente.

Pero salgamos a la ciudad con los robots.

Los robots, al carecer de la ética humana y, con ello, acercarse a la "perfección", caen en todo tipo de perversiones, miserias y bajos oficios favorecidos por el entorno urbano: estrella de cine, mafioso, prostituta... Como hemos dicho, proyectan la bajeza, lo más miserable de la ciudad. No obstante, la propia ciudad incorpora, e incluso abraza, cada una de estas degeneraciones y le otorga su espacio en su entramado. Si en cualquier momento encontramos un robot en Nueva Nueva York, podemos deducir inmediatamente que hemos entrado en un espacio más o menos hostil de la ciudad. Quizás no siempre parezca inmediatamente hostil de un modo físico, pero siempre lo será desde nuestra ética del siglo XXI. Sin embargo, a menudo, la separación entre ambas éticas -la suya y la nuestrasolo sorprende por unos segundos. Inmediatamente podemos entender que lo que parecía una exageración representada por esa máquina no dista demasiado de nuestra propia realidad.

7 Contemplar las condiciones reales de tantos hoteles japoneses, en el colmo deshumanizado del espacio vital, invita a que nos preguntemos por el camino de nuestra propia búsqueda de una exagerada eficiencia. En el fondo, existe una crítica soterrada a las políticas de economización respecto a la calidad de vida. 


\subsection{Amy y Zoidberg: la adaptada y el inadaptado}

Si bien hemos mencionado la incapacidad de la nueva ciudad para aceptar lo extraño en el ejemplo de los mutantes del mundo subterráneo, estos dos personajes serían casi un ejemplo típico de la hospitalidad de la gran ciudad hacia los inmigrantes.

Amy, la joven estudiante de la Universidad de Marte con ganas de disfrutar la gran ciudad, se adapta fácilmente a las condiciones que se le imponen. Ella explota al máximo la ciudad, abraza las novedades casi rechazando por completo y conscientemente el origen reaccionario de los padres rancheros, ricos asiáticos insoportables y sin escrúpulos. Casi un personaje típico, Amy sirve de ejemplo perfecto del extranjero adaptado a la gran ciudad.

La ciudad cumple perfectamente su papel de gran presencia anfitriona con todos sus juegos de aceptación de lo extraño, mientras se cumplan ciertas normas tradicionales. Resulta paradigmática la relación con sus padres, en la cual se desarrolla con total naturalidad aunque choque, inconciliable, con sus nuevos hábitos urbanos. Ningún ejemplo encontramos tan evidente el binomio mundo urbano/mundo rural, siempre desde la exageración paródica. La joven rebelde tiene una relación amorosa con el extraterrestre Kif, cuya apariencia desagrada absolutamente a sus padres. En el episodio (4.6.), la diferencia de lo urbano frente a lo tradicional y provinciano de los padres de Amy -unido a su superación de tales ideales de la vida-, llega a su cumbre. En este episodio, Kif para demostrar su masculinidad, tiene que combatir a los marcianos indígenas y devolver la manada de Buggalos a la familia Wong. A esa imagen típica de los padres tradicionalistas cuyo único deseo es tener nietos, se contrasta el modo de vida de Amy, quien no sólo es doctoranda en física aplicada, sino que también disfruta de todas las posibilidades de la gran ciudad, desde las discotecas ultramodernas hasta variaciones de los novios más raros.

Zoidberg, por otro lado, es el paradigma de lo extraño, de lo ajeno, de lo alienado por la ciudad, pero completamente asumido por ella y por sus múltiples perspectivas. Incapaz de salir del marco de su origen, su extrañeza se acepta, aunque ni se comprenda ni se interrelacione eficientemente con ella. A este hecho debemos añadir su completa ignorancia del oficio que desempeña ${ }^{8}$. Observamos este hecho desde el constante engullimiento de asquerosos desechos hasta la vivisección de seres humanos, sin apenas crítica ni sorpresa por parte de estos.

8 En ello quizás tengan que ver sus especialidades en "gente muerta": asesinatología y asesinatonomía. Su doctorado en Historia del Arte tampoco parece haber favorecido nada. 
Zoidberg es el inmigrante inadaptado, desfamiliarizado con tanta crudeza que la analogía con nuestra propia realidad no parece tan directa como la de otros personajes.

\subsection{Hermes}

La última paradoja dialógica que encontramos entre los protagonistas de Futurama la desarrolla el personaje de Hermes. El campeón de limbo, el gran burócrata, el eficiente contable, nos desfamiliariza respecto a la acostumbrada administración urbana. Si el tópico del funcionario, del empleado gris de las cuentas y los balances, se representa habitualmente mediante el individuo apagado, serio y aburrido, por el contrario este jamaicano alegre y vital introduce la nota optimista en la evolución de la ciudad. Si cada personaje muestra un paso más abajo en la ética y la degradación humana, Hermes se encuentra en el más alto ideal del funcionario. Desde la burocracia, entiende perfectamente la ciudad, cómo funciona, cómo sacarle su jugo y cómo resistirse a su alienación.

En este sentido, pocos edificios más emblemáticos encontramos en toda ciudad como los de las administraciones oficiales. El edificio de la Burocracia Central es el tópico de toda la vida: con sus pasillos largos y colas aún más largas de la gente que está esperando delante del edificio para dejar sus opiniones sobre el sistema burocrático; algunos de ellos esperando más de cien años (2.11.). No obstante, con el personaje de Hermes volvemos a la idea de la visión indecisamente distópico-utópica de la ciudad de Nueva Nueva York. Hermes es quien arregla las inmensas pilas de ficheros cantando, es quien termina su trabajo dos segundos antes del tiempo límite, es quien no llega a tener su promoción debido a su excesiva eficiencia y él es, al final, el alegre jamaicano que simplemente disfruta su trabajo mientras maltrata a los clientes con las peticiones absurdas; en fin, como cualquier buen burócrata.

Esperamos, con todo esto, haber demostrado que, si bien la atmósfera de la prospectiva Nueva Nueva York no ofrece cambios positivos respecto a muchos problemas de la vida en la gran ciudad, los personajes le dan un toque alegremente cariñoso. Por supuesto, existen numerosos precedentes, pero si nos quedáramos con uno, escogeríamos una verdadera obra maestra de la ironía y la parodia: la vieja Nueva York de los dibujos melancólicos de Will Eisner, con los que Futurama guarda tantas relaciones.

\section{Conclusiones}

Entre 1981 y 1986, Eisner publica Nueva York: La vida en la gran ciudad. En este cómic, se encuentra representado como en muy pocas obras la variedad y riqueza de una gran ciudad occidental y de los habitantes que la configuran. Tanto en la teleserie que hemos trabajado como en este cómic, utopía y distopía se funden por una 
misma concesión al ser humano: la ternura ante lo inevitable de nuestras bajezas y nuestras grandezas.

Con esta referencia esperamos completar un hermoso círculo de interés por la ciudad que empieza por las letras impresas de las novelas, pasa por más letras impresas, ahora complementos de dibujos en el cómic, hasta los dibujos y sonidos de las teleseries.

La ciudad evoluciona como evolucionan los lenguajes con que la representamos.

Como ya hemos visto, la parodia de Nueva Nueva York va un paso más allá de la parodia tradicional, al jugar con los principios propios de la ficción prospectiva. Si toda parodia establece un juego de espejos, así como de familiarizaciones y desfamiliarizaciones, entre elemento parodiado y parodia, en Futurama este juego va mucho más allá. La necesidad de una fuerte semantización, para favorecer la identificación y el pacto de ficción en la obra, provoca una necesidad constante de cotidianeidad en la propia parodia. Del mismo modo, al tratarse de un formato serial, como hemos visto al tratar a los personajes, los elementos de la ciudad van volviéndose cotidianos, familiares, provocando a su vez nuevos niveles de parodia.

Lo que permite todo ello es partir del principio de construcción de toda ciudad: la destrucción de lo familiar para construir la nueva urbe, sin desterrar del todo los rescoldos de lo arrasado. Esperamos que el ejemplo de los subterráneos haya sido esclarecedor en este sentido.

En el fondo, toda parodia se basa en una destrucción, y así cada ciudadano, con su correspondiente analogía respecto a los elementos de la gran ciudad, conlleva en sí mismo una destrucción mediante la ridiculización exagerada- de una idea urbana. Pero esta destrucción nunca es absoluta, sino primer paso para una reconstrucción que, en espíritu, implica el mismo elemento destruido. Por todo ello, Nueva Nueva York no es solo una parodia divertida, sino, en sí misma, un símbolo del sistema de evolución de toda ciudad. No parece descabellado afirmar, siguiendo este planteamiento, que de la propia serie se desprende una visión fugaz de la ética, que queda categorizada como mera disciplina temporal que evoluciona según la vida en la ciudad. Al fin y al cabo, toda ciudad real puede provocar que cualquier elemento escandalizador para ella se convierta finalmente en cotidiano si esperamos el tiempo suficiente; por ejemplo, mil años. Es el mismo proceso, en este caso espacial, por el cual se produce ese tópico del individuo del mundo 
rural que se escandaliza por multitud de motivos al introducirse en el mundo urbano ${ }^{9}$.

Este sistema de evolución se encuentra constituido por dos mecanismos que funcionan del mismo modo: la parodia y el juego prospectivo.

Del mismo modo, la exageración prospectiva de cada actitud ante la ciudad, y del modo en que cada personaje construye la ciudad, implica una novedad sin con ello desdecir el funcionamiento de los ciudadanos reales. Como ya se ha insistido en tantas ocasiones, la ficción prospectiva no profetiza el futuro, sino que emplea el recurso literario del motivo del futuro para indagar en el presente. A partir de este juego podríamos incluso ir más allá: que, de manera general, cualquier ciudad prospectiva implica en sí misma una parodia de una ciudad real, por serio que sea el planteamiento de la obra.

Por esto mismo, basta con añadir epítetos exagerados a cada elemento urbano para parodiarlo y desfamiliarizarnos, hasta la reflexión personal. Por consiguiente, el funcionamiento narrativo de la ciudad paródica prospectiva se basa en el mismo proceso por el cual ponemos sencillamente un nuevo adjetivo delante del nombre de la ciudad: Nueva Nueva York. Por esto mismo, podríamos incluso tomar el poemario de García Lorca y aplicarlo a esta ciudad prospectiva sin cambiar más que un par de referencias. Es prácticamente el mismo texto, lo leemos del mismo modo y trata de lo mismo: nuestras grandes ciudades.

\footnotetext{
${ }^{9}$ Numerosos elementos de la Nueva York real escandalizarían a muchos individuos que no pertenecieran a esta ciudad. Así, numerosos elementos de Nueva Nueva York escandalizan a Fry, quien pertenece a otro tiempo.
} 


\section{Bibliografía}

ASIMOV, Isaac (1941): "Razón", en Los robots, pp. 216-233. Barcelona: Martínez Roca, 1982.

BAUDRILLARD, Jean; y MORIN, Edgar (2003): La violencia del mundo. Barcelona: Paidós, 2004.

CARRIÓN, Jorge (2011): Teleshakespeare. Madrid: Errata Naturae.

CASCAJOSA VIRINO, Concepción Carmen (2007): La caja lista: Televisión norteamericana de culto. Barcelona: Laertes.

EISNER, Will (1981-1986): Nueva York: La vida en la gran ciudad. Barcelona: Norma, 2008.

FERNÁNDEZ FOLGUEIRAS, Erea (2012): Poética del fragmento: Aproximación a la experiencia del sentido en La Vie mode d'emploi de Georges Perec. Madrid: Universidad Complutense de Madrid.

GARCÍA LORCA, Cabeza de Federico (3000): Poeta en Nueva Nueva York. Groening: Sprinfield.

LOZANO MIJARES, María del Pilar (2007): La novela española posmoderna. Madrid: Arco/Libros.

MIGNOLO, Walter (1981): "Semantización de la ficción literaria". Disposición, vol. 15-16, pp. 85-127.

MORENO, Fernando Ángel (2010): Teoría de la literatura de ciencia ficción: Poética y retórica de lo prospectivo. Vitoria: Portal Editions.

- (2011a): "El monstruo prospectivo: El otro desde la ciencia ficción". Signa: Revista de la asociación española de semiótica, núm. 20, pp. 471-496.

- (2011b): "Sutileza de la razón cínica: el lenguaje narrativo de Mad Men", en J. Requena y C. Cascajosa (eds.), Mad Men: reyes de la Avenida Madison. Madrid: Capitán Swing.

MORENO, Fernando Ángel; y PALIBRK, Ivana (2011): "La ciudad prospectiva" [en línea]. Ángulo Recto. Revista de estudios sobre la ciudad como espacio plural, vol. 3, núm. 2, pp. 119-131. En: http://www.ucm.es/info/angulo/volumen/Volumen03-2/varia01.htm [Consulta: abril de 2012]. ISSN: 1989-4015. Doi: http://dx.doi.org/10.5209/rev ANRE.2011.v3.n2.37584

RICOEUR, Paul (1975): Teoría de la interpretación: Discurso y excedente de sentido. México: Siglo XXI, 1995.

SANMARTÍN ORTÍ, Pau (2008): Otra historia del formalismo ruso. Madrid: Lengua de Trapo.

SKLOVSKI, Victor (1917): "El arte como artificio", en Tzvetan Todorov (ed.) (1965), Teoría de la literatura de los formalistas rusos, pp. 55-70. México: Siglo XXI, 1970.

Los aficionados a la serie han desarrollado una página web muy útil y completa, que recomendamos:

http://futurama.wikia.com/wiki/Futurama Wiki 